\title{
A TRYPANOSOME OF CATTLE IN THE SOUTHERN SUDAN.
}

By Captain R. G. Archibald, M.B., R.A.M.C., Pathologist and Assistant Bacteriologist, Wellcome Tropical Research Laboratories, Khartoum.

THERE can be little doubt that cattle trypanosomiasis exists as a fairly common entity in certain districts of the Southern Sudan. For various reasons, chief of which is the difficulty in transport of infected animals, it has not been possible to fully work out the characters of the trypanosomes met with in the cattle of these districts. Our knowledge of them in the past has been mainly derived from the examination of blood films taken from infected animals.

Recently, however, through the kindness of Captain Walker, of the Army Veterinary Department, an opportunity presented itself of investigating the characters of a small trypanosome found in the blood of a sick cow which this officer had brought to Khartoum from Bor, a river station in the Mongalla Province. This trypanosome possessed morphological characters more or less identical with the one found and described by Balfour ${ }^{1}$ in 1905 , and which was considered by Laveran to be a new species. In view of its small size Laveran ${ }^{2}$ gave it the name of trypanosoma nanum.

Since then other observers have found small trypanosomes in cattle, and, until quite recently, a considerable amount of confusion has existed, owing to the various names ascribed to these trypanosomes.

Bruce $^{3}$ and the other members of the recent Sleeping Sickness Commission have decided, however, to group together under the name of trypanosoma pecorum the trypanosome described by Dr Edington in Zanzibar, the trypanosoma dimorphon, the trypanosoma congolense, the trypanosome found in Portuguese East Africa and Zululand and described by. Theiler, and the species found in Northern Rhodesia by Montgomery and Kinghorn and in Southern Rhodesia by Bevan.

In order to observe whether the cattle strain of trypanosome kindly supplied by Captain Walker was entitled to a position in the trypanosoma pecorum group, it was made use of in various animal inoculation experiments.

The originally infected cow died soon after its arrival in Khartoum, but the strain was maintained by inoculating a second cow and carrying out a series of sub-inoculations into other animals.

It will be convenient at this stage to give a description of the morphology of the trypanosome.

Living Unstained.-In fresh blood film preparations the trypanosome, although very active, was not possessed of great translatory movements. A noticeable feature was the tendency for this trypanosome to adhere to the erythrocytes, thereby causing considerable agitation by its peculiar butting and quivering movements. When free it showed a slight translatory movement as it glided in amongst the red cells, with its anterior end as a rule foremost. In thick blood film or in films showing marked rouleaux formation the trypanosome was frequently hidden from view by having disappeared behind 
the red cells. Except for the presence of a granule in the middle of the body its contents were apparently homogeneous.

Fixed and Stained. - The method employed for fixing and staining the specimens was that recommended by the Uganda Sleeping Sickness Commission. ${ }^{4}$ Films still moist were exposed for forty-five seconds to the vapour of 4 per cent. solution of osmic acid in water, to which a drop of glacial acetic acid had been added. The cover slips were then transferred to absolute alcohol for ten minutes, and then taken through varying grades of alcohol from 80 to 10 per cent. in distilled water. They were then stained either by Leishman's stain or by Giemsa. When the latter stain was used the film was quickly passed through orange tannin in order to differentiate more clearly the cell contents.

Length.--The trypanosome was measured by drawing its outline by means of a camera lucida at a magnification of 2000 diameters, and then measuring along the middle line of the body by means of a pair of fine compasses the points of which were separated $2 \mathrm{~mm}$. This method is simple and quick, but, as has been recently shown by Stephens and Fantham, ${ }^{5}$ does not give an absolutely accurate measurement.

The average length was I $2 \cdot 7 \mu$, with a minimum measurement of $9 \mu$ and a maximum of $20 \mu$. When stained the trypanosome was short and somewhat stout in form. Some very squat and tadpole forms were to be met with, particularly in films showing heavy infections.

The anterior extremity was narrow, while the posterior was, as a rule, blunt and rounded. Some forms, however, showed a pointed posterior extremity. The undulating membrane was fairly well developed. Apparently there was no free flagellum. The latter arose, as a rule, at a point quite close to the micro-nucleus.

Breadth. - The average breadth, including the undulating membrane, was I $4 \mu$, with a maximum measurement of $2 \mu$ and a minimum of I $\mu$.

Cell Contents.-The majority showed the presence of granules which took on a chromatin stain. The longer forms in particular showed a number of granules which, in most of the trypanosomes, were situated posterior to the nucleus. Some, however, showed the presence of granules anterior to the nucleus. Vacuoles, when present, were usually posterior to the nucleus and close to the micro-nucleus.

Nucleus.-The nucleus was oval in shape and usually situated about the centre of the body. Occasionally round forms of nuclei were met with which showed chromatin granules at their margin.

Micro-nucleus.-The micro-nucleus or kineto-nucleus was usually circular in shape. In some of the trypanosomes it occupied a terminal position, while in others it was in close proximity to the posterior extremity. In dividing and predividing forms it assumed the shape of a rod.

Undulating Membrane.-This, as a rule, was somewhat narrow and straight, but several forms were met with having two and three folds.

Flagellum.-The flagellum stained fairly intensely, and did not project beyond the protoplasm of the cell. 
Animal Inoculation Experiments.

\begin{tabular}{|c|c|c|c|}
\hline Animal. & Source of Virus. & $\mid \begin{array}{c}\text { Period of } \\
\text { Ineubation } \\
\text { in Days. }\end{array}$ & Remarks. \\
\hline Bullock (2) & $\begin{array}{l}\text { Naturally in- } \\
\text { fected bul- } \\
\text { lock (I) }\end{array}$ & I6 & Died of infection. \\
\hline Mule & Bullock (I) & 20 & $\begin{array}{l}\text { Further history of animal not } \\
\text { followed. }\end{array}$ \\
\hline Goat & Bullock (2) & Io & Died from pneumonia. \\
\hline Rabbit . . & Bullock (2) & 30 & Killed. \\
\hline Guinea-pig (I). & Bullock (2) & 35 & $\begin{array}{l}\text { Only a single trypanosome } \\
\text { found in several films that } \\
\text { were examined. No evi- } \\
\text { dence of trypanosomes the } \\
\text { following day. }\end{array}$ \\
\hline Gerbil (I) & Bullock (2) & I 3 & Died on $\mathrm{r} 6$ th day. \\
\hline Gerbil (2) & Guinea-pig (I) & - & Never showed trypanosomes. \\
\hline Gerbil (3) & Guinea-pig (I) & 一 & Never showed trypanosomes. \\
\hline Monkey (I) & Gerbil (I) & 39 & Died of trypanosomiasis. \\
\hline Monkey (2) & Monkey (I) & 32 & Killed. \\
\hline Gerbil (4) & Monkey (I) & 5 & Died in 12 days. \\
\hline Gerbil (5) & Gerbil (4) & 5 & Died in 14 days. \\
\hline Sheep. & Monkey (I) & I 3 & Died in $\mathbf{2} 2$ days. \\
\hline Cat . & Monkey (I) & I 6 & Died in 30 days. \\
\hline Donkey. & Goat & I 9 & Died after I I I days. \\
\hline Dog . & Goat & $?$ & Killed. \\
\hline Gerbil : . & Dog & I I & Died in 27 days. \\
\hline $\begin{array}{l}\text { Jerboa (Jaculus } \\
\text { gordoni) }\end{array}$ & Goat & I 4 & Died. \\
\hline
\end{tabular}

The result of the animal inoculation experiments showed that this trypanosome was pathogenic for the following animals: ox, mule, monkey, goat, sheep, rabbit, donkey, dog, gerbil, and jerboa. The guinea-pig was apparently the least susceptible animal; in fact, one might say that it enjoyed a comparative immunity to this trypanosome. The detailed experiments on the guinea-pig will be referred to later.

The Disease in Animals.—In infected bullocks the main symptoms were progressive weakness, emaciation, and anæmia. These symptoms were also common to the dog, sheep, donkey, cat, and monkey. Of the pathological signs little need be said. The spleen was invariably congested but not markedly enlarged. The liver consistently showed evidence of hyperæmia.

In the gerbil, monkey, cat, donkey, and sheep the trypanosomes multiplied steadily and progressively from the time of their first appearance in the blood till the death of the host.

In the goat there was a certain periodicity in the appearance of the trypanosomes in the peripheral blood. Sometimes they could not be found, while at other times two and three trypanosomes would be present in the same field. It was also noted that the 
trypanosomes were usually small and possessed a uniformity in length. This was also observed in the infected sheep. In the cat, however, the longer forms were more numerous than in the other animals.

The Carrier of this Trypanosome.-Owing to lack of material it was impossible to carry out any transmission experiments to prove the possible agent implicated in spreading the infection.

The previous history of the originally infected bullock showed
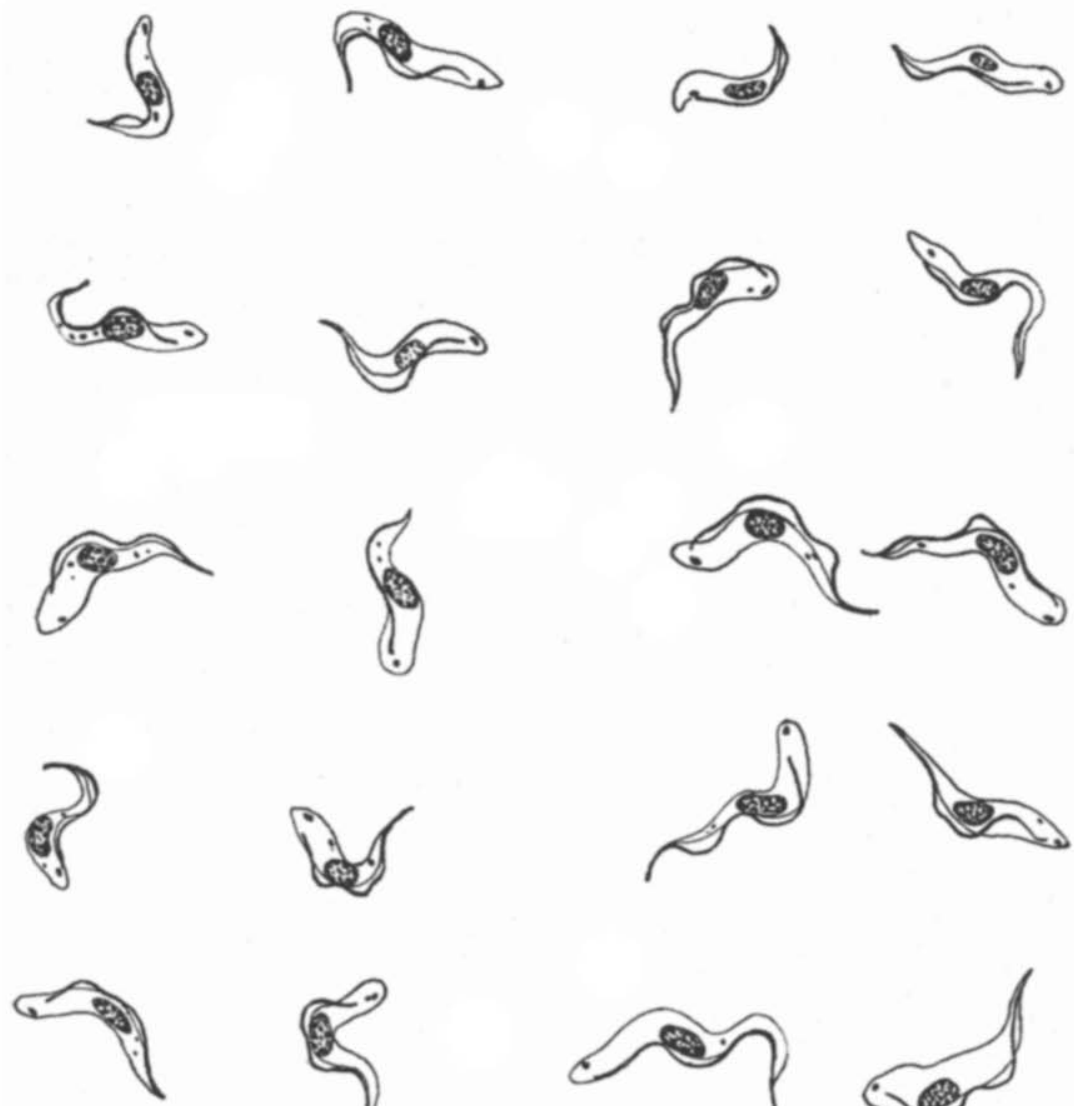

Eucharcan del
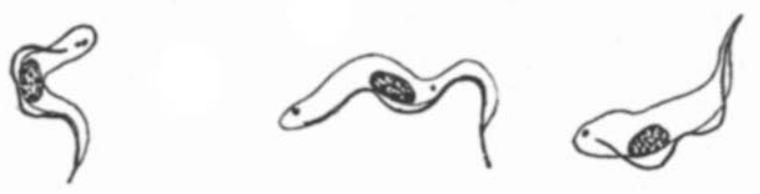

Trypanosoma of eattle (trypanosoma pecorum). Drawn with camera lucida. Oe. 12 , obj. $2 \mathrm{~mm} . \times 2000$.

that it had not travelled beyond the Bor district. One can, therefore, exculpate the tsetse fly, for it does not exist in that district. Stomoxys and tabanidæ, however, abound there, and it is more than probable that either one or other of these species of flies is concerned as the transmitting agent.

Cultivation of the Trypanosome.-This trypanosome grew fairly readily on blood agar. At the end of twenty-four hours clumps consisting of three or four trypanosomes were found with their 
flagellar ends directed outwards and displaying active motion. Short, stumpy, plasmodial forms were noticed in some of the clumps. Many of the flagellates showed vacuoles present in their cytoplasm.

At the end of forty-eight hours numerous clumps were observed showing active trypanosomes. Fewer plasmodial forms were present. The individual flagellates contained numerous chromatin-staining granules.

At the end of seventy-two hours the cultures showed the presence of numerous long forms of trypanosomes; many of these were very vacuolated and contained numerous chromatin - staining granules. Clumping was still in evidence. On the fourth day the trypanosomes appeared to be exceptionally active and quite numerous. Fewer clumps were present. Some of the trypanosomes stained quite sharply, but their flagella were not very distinct.

The trypanosomes, as a rule, did not remain alive longer than five days. After the fifth day they lost their activity, and showed, in stained specimens, evidence of degeneration.

Remarks.-In morphology and in other characters this trypanosome has many points of resemblance to the small trypanosomes that have been described as occurring in African cattle. These, as already mentioned, have been grouped by Bruce and others under the trypanosoma pecorum sp. nov., and in the writer's opinion the trypanosome described in this paper is a representative of this species. Its morphological characters, its pathogenicity towards many animals, and its cultural characters correspond in the main to those of trypanosoma pecorum.

The pathogenicity to numerous animals excluded the idea that one was at first dealing with trypanosoma nanum.

Reference has been made to the difficulty in infecting guinea-pigs. This was also experienced by Bruce ${ }^{6}$ and his colleagues. In their earlier experiments they found these animals refractory, but considered that if the trypanosome was passed by a series of inoculations into rats or rabbits it would become pathogenic to the guinea-pig. Subsequent experiments carried out by them proved that the guinea-pig could be successfully inoculated.

It will be as well now to consider in a tabulated form the writers' inoculation experiments on the guinea-pig:-

\begin{tabular}{|c|c|c|c|}
\hline Animal. & Source of Virus. & Result. & Remarks. \\
\hline Guinea-pig ( $\mathrm{I}$ ) & Bullock ( $\mathbf{r}$ ) & + & $\begin{array}{l}\text { Only one trypanosome found } \\
\text { in several fields that were } \\
\text { examined. Guinea-pig never } \\
\text { showed trypanosomes again, } \\
\text { and lived for five and a half } \\
\text { months. }\end{array}$ \\
\hline Gerbil (2) . & Guinea-pig (I) & - & Never showed trypanosomes. \\
\hline Guinea-pig (2) & Gerbil & - & Never developed trypanosomes. \\
\hline Guinea-pig (3) & Monkey & - & Never developed trypanosomes. \\
\hline Guinea-pig (4) & Cat & - & Never developed trypanosomes. \\
\hline
\end{tabular}


From the above experiments it was obvious that the guinea-pig had a marked degree of immunity to this trypanosome. Guineapig (I) was inoculated with the original strain, and its peripheral blood only showed a single trypanosome on the thirty-fifth day after inoculation. Trypanosomes were never found again in this animal.

The passage of this trypanosome through the monkey and cat failed to make it pathogenic for the guinea-pig. The monkey and cat were used, as in previous inoculation experiments it was found that the virulence of the trypanosome was increased in its passage through these animals. In spite of this, however, it still remained non-pathogenic to the guinea-pig.

Theiler found a short trypanosome in cattle which was nonpathogenic to guinea-pigs. It has not been possible to consult this observer's original paper, but from the references obtainable the Chai Chai trypanosome investigated by Theiler resembles the one which forms the subject of this paper.

Conclusions.-The trypanosome described in this paper is trypanosoma pecorum, a species causing cattle trypanosomiasis in the Southern Sudan and in other parts of Africa. From the experiments carried out it would seem that this Sudan strain of trypanosoma pecorum is non-pathogenic to guinea-pigs, differing only in this respect from the trypanosoma pecorum found in Uganda, but resembling the trypanosoma pecorum strain found by Theiler in the Chai Chai districts of Portuguese East Africa.

Previous observations on stained blood films conveyed the impression that trypanosoma pecorum was one of the possible causes of animal trypanosomiasis in the Sudan, but it was only recently that an opportunity occurred of definitely confirming its existence by means of animal and cultural experiments.

I am indebted to $\mathrm{Mr}$ George Buchanan for the plate illustrating the trypanosome, and for his assistance in the cultivation experiments.

\section{REFERENCES.}

(I) Balfour, A. "Trypanosomiasis in the Anglo-Egyptian Sudan," Edinburgh Medical Journal, September 1905.

(2) Laveran, A. Compt. Rend. Soc. de Biol., 24 th February 1905.

(3) Bruce, D., Hamerton, A. E., Bateman, H. R., and Mackie, F. P. "Trypanosome Diseases of Domestic Animals in Uganda-Trypanosoma Pecorum," Proceedings Royal Society, r9 10, B Vol. LXXXII.

(4) Bruce, D., Hamerton, A. E., and Bateman, H. R. "A Trypanosome from Zanzibar," Proceedings Royal Society, r909, B Vol. LXXXI.

(5) Stephens, J. W. and Fantham, H. B. "The Measurement of Trypanosoma Rhodesiense," Annals of Tropical Medicine and Parasitology, 3 Ist July i 9 I 2.

(6) Bruce, D., Hamerton, A. E., Bateman, H. R., and Mackie, F. P. "Trypanosome Diseases of Domestic Animals in Uganda-Trypanosoma Pecorum," Proceedings Royal Society, r 9 10, B Vol. LXXXII. 